Dementia as an existential threat: the importance of self-esteem, social connectedness and meaning in life.

Authors: Richard Cheston, Gary Christopher and Sanda Ismail

A commentary for submission to Science Progress

Key words: Dementia; Alzheimer's Disease; Mnemic Neglect; Nostalgia; selfesteem; social connectedness; meaning in life; existential threat.

Institutional affiliation:

Health and Social Sciences

Department of Health and Applied Sciences

University of the West of England

Frenchay Campus

Coldharbour lane

Bristol

BS16 9AY

Address for correspondence: richard.cheston@uwe.ac.uk 


\title{
Dementia as an existential threat: the importance of self-esteem, social connectedness and meaning in life.
}

\begin{abstract}
As Dementia is one of the most feared of all illnesses, it is important that our understanding of the psychological impact of the illness addresses the way in which dementia represents an existential threat. Research over the last 20 years has consistently indicated that higher levels of self-esteem and social connectedness and a greater sense of meaning in life all buffer people against such threats. Applying this framework to dementia care may enable us to understand more about the psychological functions of forgetting, as well as reframing the use of the past by some people affected by dementia as an attempt to generate a life of meaning and connectedness. Finally, it may help to generate new methods of intervening such as the therapeutic use of nostalgia.
\end{abstract}




\section{Dementia as an existential threat: the importance of self-esteem, social connectedness and meaning in life.}

Dementia is an umbrella term for a large number of illnesses, all of which involve neurodegenerative changes in the brain. The most common forms of dementia are Alzheimer's disease and vascular dementia, but there are over 100 other, rarer conditions. All of these different illnesses involve a progressive decline of cognitive functions in which symptoms gradually spread, so that eventually almost all areas of cognitive functioning are affected. Over time, these cognitive changes compromise the person's practical ability to manage everyday activities, leading to increasing levels of dependency on those around them. At present there is no cure for any form of dementia.

If we are to achieve an understanding of the psychological impact of dementia, then we also need to understand the way in which dementia acts as an existential threat. Dementia can compromise identity, challenge independence, prompt social isolation and threaten our ability to find meaning and purpose in life. Thus, a 2014 YouGov poll commissioned by Channel Five news in the UK found that fear of dementia was greater than fear of cancer, particularly amongst older people (1).

\section{Managing existential threat}

Over the last twenty years, an established body of literature has emerged that has detailed the way in which people respond to threats. To date, this body of work has been largely conducted from a social psychology perspective. However, we believe that the insights that have steadily accumulated may help us to develop a much better understanding of how people respond to dementia. This 
in turn may help us to improve a number of different areas of dementia care.

This work clearly points to three, linked factors that play a crucial role in helping to prevent anxiety when people are confronted by threats including reminders of their own mortality: self-esteem, social connectedness and meaning in life. People who score highly on all three of these factors seem to be more able to think about the nature of the threat that they face without becoming overwhelmed with anxiety. In other words people who feel good about themselves and who feel more connected to the world around them are also better able to find meaning and purpose in life even when they are reminded that life can be short, brutal and nasty.

Given the importance of self-esteem, social connectedness and meaning in life in enabling people to tolerate threats to their identity, it follows that it is important within dementia care both to understand the consequences of low self-esteem and to identify methods of increasing this.

\section{Forgetting is a psychological defence as well as a neurological symptom.}

As humans we are good at putting up mental barriers that help to prevent us from being disturbed by threats to our self-esteem. Research suggests that there is a pattern of selective forgetting in which memories that enhance our self-esteem are better recalled - a phenomena that has been termed mnemic neglect. For instance, if we are asked to remember two types of feedback, some of which is positive and enhances self-esteem and some of which is negative, then we are more likely to remember the negative information if it relates to another person than to ourselves. Memory, then, seems to act in a self-protective fashion. If mnemic neglect occurs in the same way for people 
affected by dementia as it does amongst the general population, then this may help to explain why some people who are affected by dementia struggle to recall information about their illness. In addition, research also indicates that under certain circumstances mnemic neglect disappears. This is the case, for instance, when information is provided by a close friend (2), when the information is about traits that are changeable (3), or which are not highly negative (4). Understanding more about how mnemic neglect operates with people affected by dementia may help us to go on to develop more effective ways of talking to people with dementia about their illness. We are currently working on a study funded by the Alzheimer's Society to look at just these possibilities (5).

2. Retreating into a cultural world view. The principal way in which we can increase our self-esteem is to invest ourselves in the social frameworks through which merit, value and worth are calculated. To put this another way, we invest ourselves in what are termed cultural world views - those widely held ways of thinking about the world through which people achieve a sense of meaning, identity and purpose. For some, this might be through a belief in the importance of their nation, whilst for others it might be through religious faith (6).

Within the context of dementia care, this retreat into a worldview established in past years can perhaps be seen when people who are affected by dementia assert that they still do the same things in their life now as they have always done and that nothing in their lives has changed. Often the significance of this apparent retreat into the past is disregarded as either a relatively harmless 
sign of confusion, or as a Behavioural and Psychological Symptom of Dementia that is in need of treatment.

From an existential perspective, however, this is not so much a retreat into the past but rather a method of promoting self-esteem, building social connectedness and asserting the continued relevance of a world in which life had meaning and substance. As such, this provides a method of buttressing the person against the existential realities of their current life. A personcentred response to this behaviour would be to build a compassionate social environment in which the person could have their unmet need for selfesteem, social connectedness and meaning in life met and be gently encouraged to engage with the world around them (7).

3. Using nostalgia to build self-esteem. While reminiscence has been one of the most extensively investigated areas of dementia care, the bitter-sweet emotion of nostalgia has been relatively over-looked. Although reminiscence and nostalgia are linked, there is one important difference: while reminiscence involves remembering events from one's past (8), these events may not necessarily evoke any feelings. On the other hand, nostalgic recollections of the past are full of feelings (9). In other words, it is the sentimental component of some reminiscences that makes them nostalgic. As Batcho comments: "One can remember without being nostalgic, but one cannot be nostalgic without remembering" (10).

The re-creation of nostalgic feelings for individuals has been shown to have important psychological effects. First of all, nostalgia seems to be triggered by loneliness. In other words, people who are lonely seem to be more likely to 
be nostalgic (11). Moreover, nostalgia also seems to help people to feel more positive about themselves, and also to feel closer to other people (12). Thus, nostalgia both acts to increase social connectedness in a way that nonnostalgic memories do not (13) and to also increase self-esteem (14).

Within dementia care, this distinction between reminiscence and nostalgia is important as reminiscence therapy is frequently used as an intervention even though a number of recent research studies have failed to find any significant benefits (15). We would suggest that these disappointing findings may be accounted for by findings from social psychology: thus, there is enormous individual variation in what people find nostalgic, with some people (including habitual worriers) not showing any benefit at all. This suggests that nostalgic reminiscence should be provided as a be-spoke intervention that is targeted on those who are most likely to benefit. Moreover, as the affective qualities of nostalgic recollection can be triggered by a wide variety of external stimuli including music, smells, possessions, products and objects, a focus on nostalgia opens the door for a variety of innovative ways of engaging with people affected by dementia $(16,17,18$ and 19$)$. Within the framework we have put forward, then, there are strong arguments for considering nostalgia as the active component of therapeutic success in Reminiscence Therapy, an issue that we are exploring in an on-going study (20).

In conclusion, we believe that there are important reasons to reframe dementia as an existential threat: for researchers, this opens up a rich seam of possibilities; while for clinicians and carers, it opens the door to new ways of thinking about 
how to engage with people who are affected by dementia when they are in distress. Most importantly, for people affected by dementia, we believe that this approach will help them to find better ways of coping with the awful, threatening terror of dementia. 


\section{References}

1. http://www.channel5.com/shows/5-news/features-archived/channel-5$\underline{\text { news-poll-people-fear-dementia-warning-more-than-cancer-research }}$ (accessed 7th October, 2015)

2. Green J, Sedikides C, Pinter B, van Tongeren D (2009) Two Sides to Selfprotection: Self-improvement Strivings and Feedback from Close Relationships Eliminate Mnemic Neglect, Self and Identity, 8: 233-250

3. Green, J.D., Pinter, B. and Sedikides, C. (2005) Mnemic neglect and self threat: Trait modifiability moderates self protection. European Journal of Social Psychology, 35 (2), pp.225-235.

4. Green J and Sedikides C (2004) Retrieval Selectivity in the Processing of Selfreferent Information: Testing the Boundaries of Self-protection, Self and Identity, 3 (1), 69-80

5. http://www.controlledtrials.com/ISRCTN30485698?q=\&filters=conditionCategory:Nervous\%20S ystem\%20Diseases\&sort=\&offset=22\&totalResults=528\&page=1\&pageSiz e $=100 \&$ searchType $=$ basic-search

6. Solomon, S., Greenberg, J. and Pyszczynski, T. (1991) A terror management theory of social behavior: the psychological functions of self-esteem and cultural worldviews. Advances in Experimental Social Psychology, 24, 93159

7. James, I.A. (2011) Understanding Behaviour in Dementia that Challenges: $A$ Guide to Assessment and Treatment, London: Jessica Kingsley Publishers. 
8. Coleman, P.G. (2005) Uses of reminiscence: Functions and benefits, Aging and Mental Health, 9 (4), 291-294.

9. Sedikides, C., Wildschut, T. and Baden, D. (2004) Conceptual Issues and Existential Functions. in J. Greenberg, S. Koole, \& T. Pyszczynski (Eds.), Handbook of Experimental Existential Psychology (pp. 200-214). New York, NY: Guilford Press.

10. Batcho, K.I. (2007) Nostalgia and the emotional tone and content of song lyrics. The American Journal of Psychology, pp.361-381

11. Zhou X, Sedikides C, Wildschut T and Gao D-G (2008) Counteracting Loneliness On the Restorative Function of Nostalgia, Psychological Science, 19 (10), 1023-1029.

12. Hart, C. M., Sedikides, C., Wildschut, T., Arndt, J., Routledge, C., \& Vingerhoets, A. J. J. M. (2011). Nostalgic recollections of high and low narcissists. Journal of Research in Personality, 45, 238-242.

13. Wildschut, T., Sedikides, C., Arndt, J., \& Routledge, C. (2006). Nostalgia: Content, triggers, functions. Journal of Personality and Social Psychology, 91, 975-993.

14. Routledge, C., Arndt, J., Wildschut, T., Sedikides, C., Hart, C. M., Juhl, J., Vingerhoets, A. J. J. M., \& Schlotz, W. (2011). The past makes the present meaningful: Nostalgia as an existential resource. Journal of Personality and Social Psychology, 101, 638-652

15. Woods RT, Bruce E, Edwards RT, Elvish R, Hoare Z, Hounsome B, Keady J, Moniz-Cook ED, Orgeta V, Orrell M, Rees J and Russell IT (2012) REMCARE: 
reminiscence groups for people with dementia and their family caregivers effectiveness and cost-effectiveness pragmatic multicentre randomised trial, Health Technology Assessment, 16(48): v-xv, 1-116. doi: $10.3310 /$ hta 16480

16. Barrett, F.S., Grimm, K.J., Robins, R.W., Wildschut, T., Sedikides, C. and Janata, P. (2010) Music-evoked nostalgia: affect, memory, and personality. Emotion, 10 (3), pp.390.

17. Janata, P., Tomic, S.T. and Rakowski, S.K. (2007) Characterisation of musicevoked autobiographical memories. Memory, 15 (8), pp.845-860

18. Reid, C. A., Green, J. D., Wildschut, T., \& Sedikides, C. (2015). Scent-evoked nostalgia. Memory, 23, 157-166.

19. Waskul, D.D., Vannini, P. and Wilson, J. (2009) The aroma of recollection: Olfaction, nostalgia, and the shaping of the sensuous self. The Senses and Society, 4 (1), pp.5-22

20. Ismail S, Cheston R and Christopher G (2014). The psychological impacts of nostalgia for people with dementia, BioMedCentral, DOI 10.1186/ISRCTN54996662, http://www.isrctn.com/ISRCTN54996662 accessed on-line, 20 $0^{\text {th }}$ October, 2015 